\title{
Bridge to transplant experience: Factors influencing survival to and after cardiac transplant
}

\author{
Nicholas G. Smedira, MD, ${ }^{\mathrm{a}, \mathrm{b}}$ Katherine J. Hoercher, RN, ${ }^{\mathrm{a}, \mathrm{b}}$ Dustin Y. Yoon, MS, ${ }^{\mathrm{a}}$ \\ Jeevanantham Rajeswaran, MSc, ${ }^{\mathrm{c}}$ Lynne Klingman, MT, CHS, ${ }^{\mathrm{d}}$ Randall C. Starling, MD, MPH, ${ }^{\mathrm{b}, \mathrm{e}}$ and \\ Eugene H. Blackstone, MD $^{\mathrm{a}, \mathrm{c}}$
}

Objective: Balancing longer duration of mechanical circulatory support while awaiting functional recovery against the increased risk of adverse events with each day on support is difficult. Therefore, we investigated the complex interplay of duration of mechanical circulatory support and patient and device factors affecting survival on support, as well as survival after transplantation.

Methods: From December 21, 1991, to July 1, 2006, mechanical circulatory support was used in 375 patients as a bridge to transplantation, with 262 surviving to transplant. Implantable pulsatile devices were used in 321 patients, continuous flow was used in 11 patients, a total artificial heart was used in 5 patients, external pulsatile devices were used in 34 patients, and extracorporeal membrane oxygenation was used in 68 patients. Two time-related models were developed: (1) a competing-risks multivariable model of death on mechanical circulatory support, with modulated renewal for each sequential support mode; and (2) a model of death after transplant in which patient factors and duration of mechanical circulatory support were investigated as risk factors.

Results: Survival after initiating mechanical circulatory support, irrespective of transplantation, was $86 \%$ at 30 days, $55 \%$ at 5 years, and $41 \%$ at 10 years; survival was $94 \%, 74 \%$, and $58 \%$ at the same time intervals, respectively, after transplantation in those surviving the procedure. Risk factors for death included longer, but not shorter, duration of mechanical circulatory support, use of multiple devices, global sensitization, and poor renal function.

Conclusion: Initiating mechanical circulatory support early with a single definitive device may improve survival to and after cardiac transplantation. Early transplant, which avoids infection, sensitization, and neurologic complications, may improve bridge and transplant survival. (J Thorac Cardiovasc Surg 2010;139:1295-305)

\section{Supplemental material is available online.}

Large multicenter heart transplant databases consistently identify duration of mechanical circulatory support (MCS) as a risk factor for posttransplant mortality, ${ }^{1-3}$ but determining optimal timing of transplantation after bridging is difficult. We and others have recommended supporting patients 1 to 3 months for organ and functional recovery to maximize survival after transplantation. ${ }^{4}$ Corroborating this approach

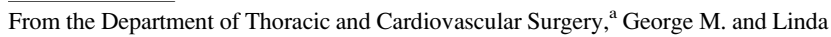
H. Kaufman Center for Heart Failure, ${ }^{b}$ Department of Quantitative Health Sciences $^{\mathrm{c}}{ }^{\text {Allogen Laboratories, }}{ }^{\mathrm{d}}$ and Department of Cardiovascular Medicine, ${ }^{\mathrm{e}}$ Cleveland Clinic, Cleveland, Ohio.

D.Y.Y. supported by the American Heart Association Pre-doctoral Fellowship. E.H.B. supported in part by the Kenneth Gee and Paula Shaw, PhD, Chair in Heart Research.

Disclosures: None.

Presented at the 87th annual meeting of the American Association for Thoracic Surgery, May 5-9, 2007, Washington, DC

Received for publication May 3, 2007; revisions received Nov 13, 2009; accepted for publication Dec 7, 2009.

Address for reprints: Nicholas G. Smedira, MD, Surgical Director, Kaufman Center for Heart Failure, Department of Thoracic and Cardiovascular Surgery, Cleveland Clinic, 9500 Euclid Avenue/J4-1, Cleveland, OH 44195 (E-mail: smedirn@ccf. org).

$0022-5223 / \$ 36.00$

Copyright (c) 2010 Published by Elsevier Inc. on behalf of The American Association for Thoracic Surgery

doi:10.1016/j.jtcvs.2009.12.006 are data from the Cardiac Transplant Research Database, International Society for Heart and Lung Transplantation, and United Network for Organ Sharing (UNOS) that consistently demonstrate reduced survival if transplantation occurs within 2 weeks or after 6 months of initiating MCS., Although there are intuitive merits to waiting, we questioned its validity when risk factors and complications not present at initiation of support delayed transplantation or when device failures or device-related strokes or infections forced urgent transplantation. Previous studies focusing only on survival after transplantation of bridged patients have not accounted for this morbidity and mortality during MCS; doing so may influence optimal timing of transplantation. Therefore, we investigated the complex interplay of duration of MCS and patient and device factors affecting survival on MCS, as well as survival after transplantation.

\section{PATIENTS AND METHODS \\ Patients}

From December 21,1991, to July 1, 2006, 375 patients determined to be transplant candidates were supported with multiple forms of MCS as a bridge to transplantation. Of these, 262 received transplants through December 2006. Patients on MCS who at the outset were not transplant candidates or were bridged to recovery were excluded.

\section{Data}

Primary data were collected concurrently with patient care as part of the Unified Transplant Database, Cardiovascular Information Registry, and 


\author{
Abbreviations and Acronyms \\ $\mathrm{ECMO}=$ extracorporeal membrane oxygenation \\ HLA = human leukocyte antigen \\ LVAD $=$ left ventricular assist device \\ MCS = mechanical circulatory support \\ PRA = panel reactive antibody \\ UNOS $=$ United Network for Organ Sharing
}

Transplant and Allogen databases. All have been approved for use in research by the institutional review board, with patient consent waived. Charts were reviewed to confirm data or add missing values. Using these, we investigated pre-device, post-device, and transplant variables, patient demographic and clinical characteristics (Table 1), device type, and complications after device insertion. Three variables deserve specific elaboration.
Number of devices. Number of devices represents the sequence of modes of MCS required for cardiopulmonary stabilization; 267 patients had only 1 device, 87 patients had 2 devices, 19 patients had 3 devices, and 2 patients had 4 devices (Figure 1). Initiation of MCS was considered the first device regardless of its traditional designation as a "short-" or "long-term" device. We chose to do this because (a) characterization of the terms "short-" and "long-term" for devices is arbitrary and inconsistently used; (b) time zero for bridging began when the first device was inserted; (c) 9 patients underwent transplantation directly from short-term MCS (extracorporeal membrane oxygenation [ECMO] and Abiomed BVS 5000 systems [ABIOMED, Inc, Danvers, Mass); and (d) we wanted to determine whether sequential devices affected survival to and after transplantation (Figure 2), and the study was designed to assess survival from the time of MCS initiation.

Global sensitization. Defining sensitization during MCS is complex. Panel reactive antibody (PRA) screening methods and threshold for treatment vary widely among centers, ${ }^{7}$ and PRA levels during MCS are volatile and nonspecific, increasing early after MCS initiation and returning to

TABLE 1. Patient characteristics

\begin{tabular}{|c|c|c|c|c|c|}
\hline \multirow[b]{2}{*}{ Characteristic } & \multicolumn{2}{|r|}{ At MCS } & \multicolumn{2}{|r|}{ At transplant } & \multirow{2}{*}{$\begin{array}{l}\text { Change* from MCS to transplant } \\
\text { (15th/50th/85th percentiles) }\end{array}$} \\
\hline & $\mathbf{n} \dagger$ & No. $(\%)$ or mean \pm SD & $\mathbf{n} \dagger$ & No. $(\%)$ or mean \pm SD & \\
\hline \multicolumn{6}{|l|}{ Demography } \\
\hline Age (y) & 375 & $53 \pm 12$ & 262 & $53 \pm 11$ & - \\
\hline Female & 375 & $65(17)$ & 262 & $39(15)$ & - \\
\hline Race & 374 & & 261 & & \\
\hline Caucasian & & $326(87)$ & & $230(88)$ & - \\
\hline African-American & & $41(11)$ & & $28(11)$ & - \\
\hline Other & & $7(1.9)$ & & $3(1.2)$ & - \\
\hline Height $(\mathrm{cm})$ & 366 & $174 \pm 9.08$ & 263 & $174 \pm 8.6$ & $-0.04 / 0.0 / 0.0$ \\
\hline Weight $(\mathrm{kg}) \ddagger$ & 282 & $83 \pm 18$ & 262 & $85 \pm 16$ & $-0.1 / 0.0 / 0.0$ \\
\hline \multicolumn{6}{|l|}{ Comorbidity } \\
\hline Creatinine $(\mathrm{mg} / \mathrm{dL}) \ddagger$ & 322 & $1.72 \pm 0.88$ & 255 & $1.2 \pm 0.56$ & $-0.2 / 0.3 / 1.0$ \\
\hline Bilirubin $(\mathrm{mg} / \mathrm{dL}) \ddagger$ & 314 & $1.73 \pm 1.38$ & 229 & $0.92 \pm 1.01$ & $-0.2 / 0.6 / 1.7$ \\
\hline BUN $(\mathrm{mg} / \mathrm{dL}) \ddagger$ & 318 & $38 \pm 22$ & 252 & $21 \pm 13$ & $-4 / 11 / 36$ \\
\hline Hematocrit $(\%) \ddagger$ & 288 & $33 \pm 5.3$ & 165 & $30 \pm 4.7$ & $-3.7 / 3.0 / 9.2$ \\
\hline Hemoglobin $(\mathrm{mg} / \mathrm{dL}) \ddagger$ & 195 & $19 \pm 11$ & 182 & $17 \pm 10$ & $-1.7 / 1.7 / 7.1$ \\
\hline BP in systole $(\mathrm{mm} \mathrm{Hg}) \ddagger$ & 239 & $96 \pm 17$ & 68 & $122 \pm 23$ & $-63 /-28 /-1$ \\
\hline BP in diastole $(\mathrm{mm} \mathrm{Hg}) \ddagger$ & 229 & $57 \pm 12$ & 68 & $65 \pm 12$ & $-25 /-11 / 4$ \\
\hline $\mathrm{T}-\mathrm{PRA}>10 \%$ & 239 & $40(17)$ & & - & - \\
\hline Cardiac index $\ddagger$ & 265 & $1.87 \pm 0.46$ & & - & - \\
\hline Cardiogenic shock $\ddagger$ & 306 & $134(44)$ & 68 & $2(2.9)$ & - \\
\hline Previous cardiac surgery & 338 & 149 (44) & & - & - \\
\hline \multicolumn{6}{|l|}{ Indication for transplant } \\
\hline Ischemic cardiomyopathy & 375 & $223(59)$ & 262 & $156(60)$ & - \\
\hline Dilated cardiomyopathy & 375 & $126(34)$ & 262 & $90(34)$ & - \\
\hline Other & 375 & $26(6.9)$ & 262 & $16(6.1)$ & - \\
\hline Support & & & 262 & & \\
\hline IABP & 375 & $304(81)$ & & $16(6.1)$ & $-\S$ \\
\hline Inotropes & 346 & $312(90)$ & & $27(10)$ & —" \\
\hline Ventilator & 375 & $294(78)$ & & $16(6.1)$ & -9 \\
\hline Medical condition & 312 & & 252 & & \\
\hline ICU & & $309(99)$ & & $176(70)$ & - \\
\hline Home (not hospital) & & $1(0.32)$ & & 49 (19) & - \\
\hline Hospital (not ICU) & & $2(0.64)$ & & $27(11)$ & - \\
\hline
\end{tabular}

$B P$, Blood pressure; $B U N$, blood urea nitrogen; $I A B P$, intra-aortic balloon pumping; $M C S$, mechanical circulatory support; $S D$, standard deviation; $T$ - $P R A, T$-cell panel reactive antibody. *Value at time of MCS minus value at time of transplant. †Data available. $\ddagger$ Data collected within 72 hours of transplant. §Of 262 patients who had a transplant, $223(85 \%)$ had IABP at time of MCS and $11(4.9 \%)$ remained on IABP until transplant. "Of 262 patients who had a transplant, $225(86 \%)$ were receiving inotropes at time of MCS and $23(10 \%)$ remained on inotropes until transplant. $\lceil$ Of 262 patients who had a transplant, $218(83 \%)$ were on a ventilator at time of MCS and $11(5.0 \%)$ remained on a ventilator until transplant. 


\section{Sequence of MCS Support}

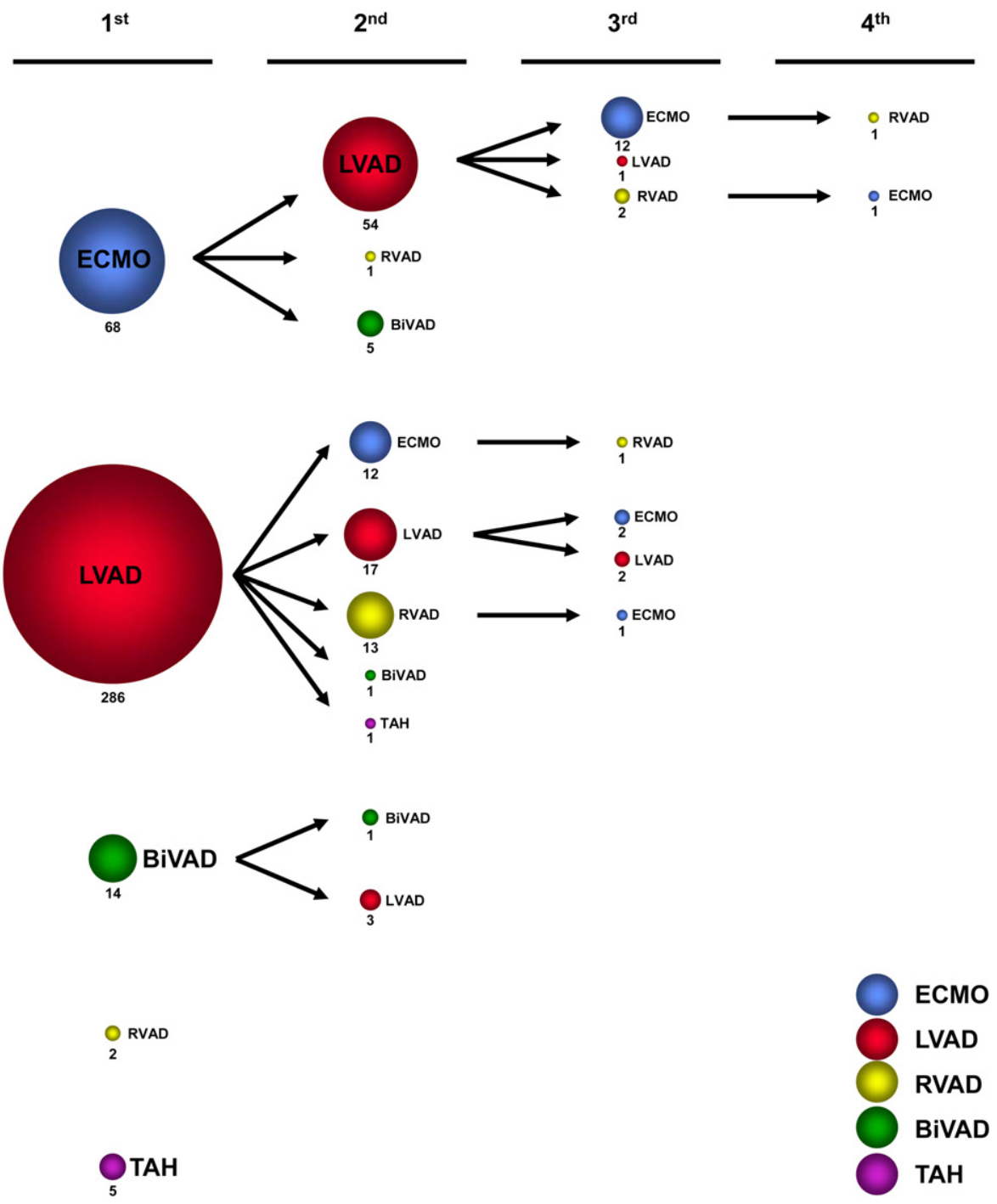

FIGURE 1. Sequence of MCS. The volume of each sphere is proportional to the number of patients who received that support device.

baseline within weeks. ${ }^{8}$ Identifying the quantity and specificity of human leukocyte antigen (HLA) antibodies has improved with evolution from complement activation cytotoxicity (standard definition of PRA $>10 \%$ ) to cellular flow cytometry to single HLA bead flow cytometry. Specific high-level antibody presence was determined by histocompatibility experts who recommended desensitization and immunosuppressive therapies. Thus, global sensitization was defined as presence of T-cell PRA more than $10 \%$ or high levels of antibody against specific HLA antigens. These patients are managed with pretransplant plasmapheresis or use of induction therapy with OKT3 or antithymocyte globulin.

Cardiogenic shock. Of our 375 patients, 306 had adequate data available to classify them as being in cardiogenic shock or not (defined as systolic blood pressure $<80 \mathrm{~mm} \mathrm{Hg}$ or cardiac index $<1.8 \mathrm{~L} / \mathrm{m}^{2}$ ). Of the 306 patients, $134(44 \%)$ were in cardiogenic shock at the initiation of MCS. Of these patients, 123 (92\%) were initially supported with a left ventricular assist device (LVAD), 8 (6\%) with ECMO, $2(1.5 \%)$ with a biventricular assist device, $1(0.75 \%)$ with a total artificial heart, and $0(0 \%)$ with a right ventricular assist device.

\section{End Points and Strategy}

Survival was assessed 3 ways: (1) overall, with time zero being inception of MCS; (2) on MCS to transplantation; and (3) after transplantation. Posttransplant survival and cause of death were determined as part of annual UNOS follow-up using UNOS definitions for cause of death (see www. unos.org). Mean follow-up was $6.2 \pm 3.7$ years, with 1402 patient-years of data available for analyses.

\section{Data Analysis}

Strategy. Analytic strategy was that of a multistate, competing-risks process, with modulated renewal for each sequential mode of support. ${ }^{9}$ Specifically, death on MCS and transplantation were considered competing risks. However, the hazard functions for death on MCS after each sequential mode had similar time-varying contours, suggesting modulated renewal. This permitted incorporating into the analysis of death on MCS cumulative events occurring with previous modes. Death after transplant was the final state considered. In addition, overall all-cause mortality after initiating MCS 


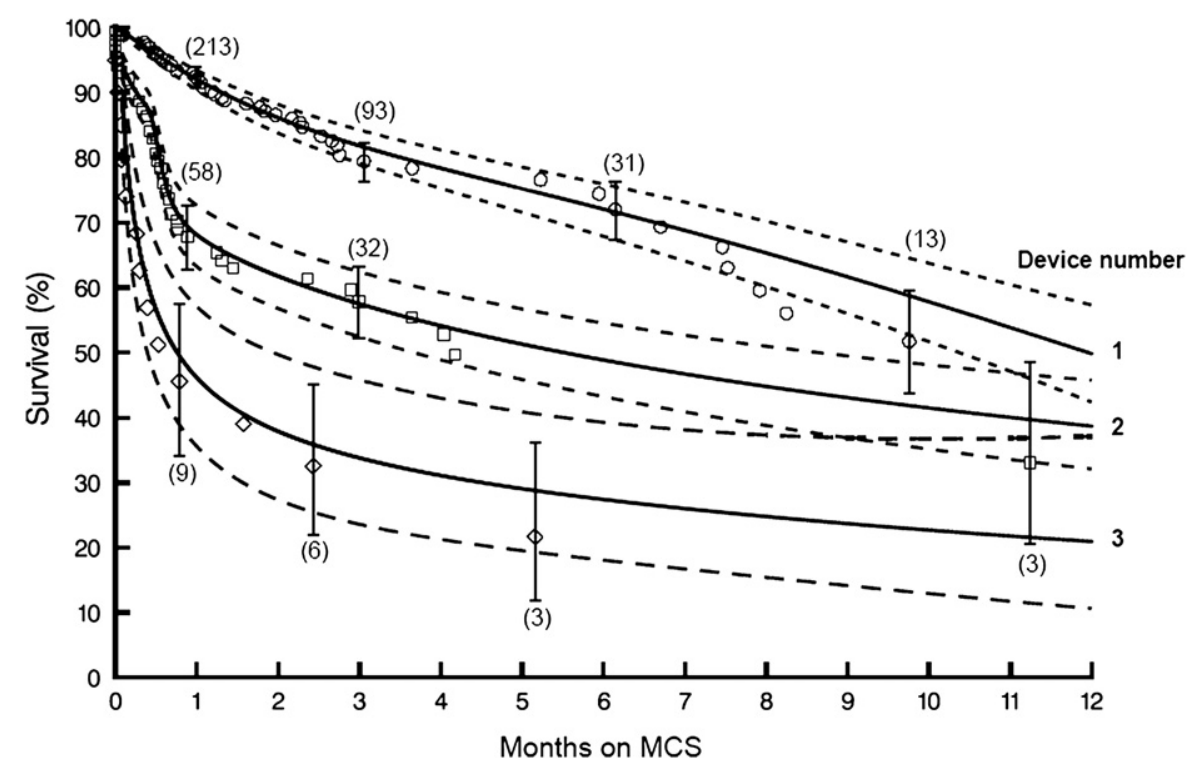

FIGURE 2. Survival while on each MCS device. This so-called modulated renewal format censors patients when another device is used or transplant occurs. Time zero is reset at each sequential change in mode of MCS. Each symbol represents a death, vertical bars represent $68 \%$ confidence limits (equivalent to \pm 1 standard error), and numbers in parentheses represent patients remaining at risk.

provided, irrespective of whether the patient underwent transplantation, an estimate of salvage of patients after initiating MCS. Survival was estimated nonparametrically by the Kaplan-Meier method and parametrically by hazard function decomposition. ${ }^{10}$ (For additional details, see http://www. clevelandclinic.org/heartcenter/hazard.)

Multivariable analyses. Multivariable analyses were performed in the hazard function domain using bagging for variable selection. ${ }^{11}$ Briefly, 500 bootstrap data sets were analyzed by automated stepwise variable selection at $P=.05$. These models were aggregated by selecting variables appearing in approximately $50 \%$ or more of models. Incremental risk factor table entries are accompanied by an estimate of Reliability (\%), which quantifies the probability that the $P$ value given in the table is actually less than .05 .

Pre-MCS variables considered in variable selection for death on MCS are listed in Appendix E1. In addition, for each modulated renewal segment, MCS sequence number; mode; whether support was left sided, right sided, or both; sequence of devices used; duration of previous segment; accumulated time on MCS; and adverse nonfatal events occurring before that mode were examined. These time-varying covariables are directly and simply incorporated in the context of modulated renewal.

Pretransplant variables considered in variable selection for death after transplant are listed in Appendix E1. Of note, these included variables related to MCS modes, adverse events while on MCS, changes in variables while on MCS, and sensitization variables. As prespecified, duration of MCS was forced into this model, and investigation of polynomial transformations of scale was made to detect the previously described ${ }^{2}$ peaking relationship.

Optimal timing of transplant. We conventionally chose to portray 5-year survival after initiation of MCS as a function of its duration. The probability of surviving both MCS and transplantation is the product of survival after initiating MCS (duration of MCS) and survival after transplantation at 5 years minus duration of MCS.

In addition to non-risk-adjusted portrayals, we have simulated a number of scenarios based on risk factors for death on MCS and after transplant. A baseline low-risk patient was defined as aged 54 years with a body surface area of $2.04 \mathrm{~m}^{2}$, pre-MCS creatinine level of $1.7 \mathrm{mg} / \mathrm{dL}$, pre-MCS bilirubin level of $1.74 \mathrm{mg} / \mathrm{dL}$, pre-MCS diastolic blood pressure of $58 \mathrm{~mm} \mathrm{Hg}$, pre-MCS pulmonary artery systolic pressure of $52 \mathrm{~mm} \mathrm{Hg}$, cardiac index of $1.9 \mathrm{~L} / \mathrm{min} / \mathrm{m}^{2}$, pre-MCS intraaortic balloon pump, pretransplant blood urea nitrogen of $19 \mathrm{mg} / \mathrm{dL}$, no previous cardiac operation, single MCS (not LVAD), MCS duration of 2.5 months, and a neurologic complication while on MCS. A series of nomograms were constructed on the basis of changes to these baseline characteristics, which are specified in Figures 3 and 4.

\section{RESULTS \\ Risk-Unadjusted Survival}

Risk-unadjusted survival after initiating MCS, irrespective of transplantation, was $86 \%$ at 30 days, $69 \%$ at 6 months, $65 \%$ at 1 year, $55 \%$ at 5 years, and $41 \%$ at 10 years (Figure 5). Risk-unadjusted survival on MCS before transplantation was $84 \%$ at 1 month, $73 \%$ at 3 months, $62 \%$ at 6 months, and $45 \%$ at 12 months (Figure E1); however, half the patients were supported less than about 2 months and $10 \%$ of patients were supported for more than 6 weeks. Of 262 patients surviving to transplantation, subsequent riskunadjusted survival was $94 \%$ at 30 days, $74 \%$ at 5 years, and $58 \%$ at 10 years (Figure E2). Two hazard phases were resolved: a high early phase that gave way to a constant hazard approximately 1 month after transplant.

\section{Risk Factors for Death on Mechanical Circulatory Support}

Both younger and older patients (Figure 3, $A$ ) and those who received non-LVAD devices (Figure $3, B$ ) were at higher risk of dying on MCS (Table 2). Survival on MCS decreased more rapidly with each sequential mode of MCS (Figure 4). Patients who had lower pulmonary arterial pressures experienced better survival. Any MCS mode other than an LVAD at MCS initiation (Figure E3, $A, B$ ) was associated with considerably higher risk of death. Of note, the specific sequence of devices and duration of support 

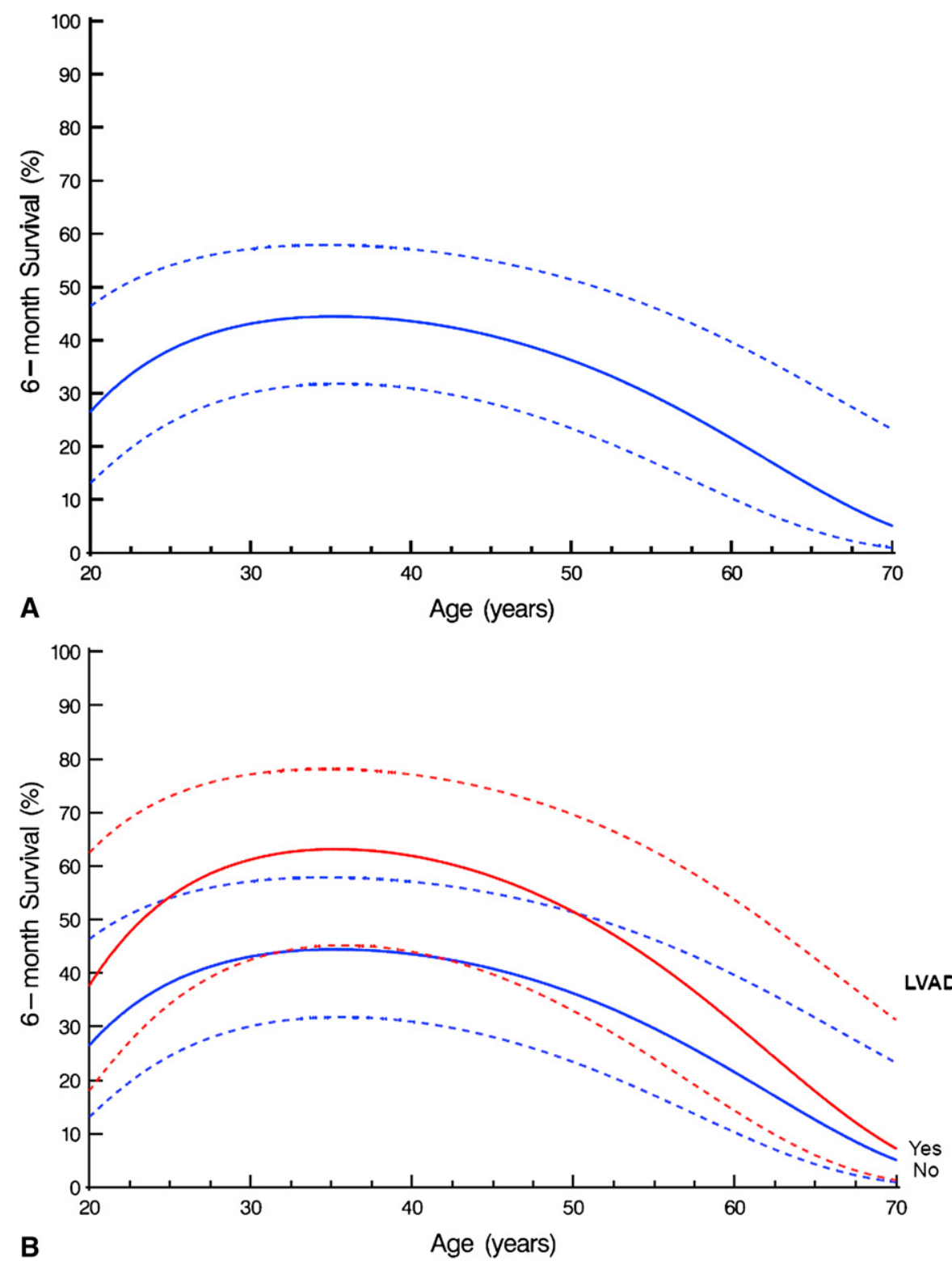

FIGURE 3. Predicted 6-month survival on MCS. Depicted are baseline patient characteristics and differences in age. A, Survival according to age. B, Survival according to age and whether or not the patient was on LVAD support.

did not increment risk above that already accounted for by sequence number and mode of support.

\section{Risk Factors for Death After Transplantation}

Early transplantation (short MCS duration) did not adversely affect posttransplant survival, and there were no statistically significant survival differences with respect to clinical characteristics between the 44 patients $(17 \%)$ who underwent transplantation within 4 weeks of initiating MCS and those undergoing transplantation later. Longer duration of support adversely affected posttransplant survival, although this relation could be due to chance $(23 \%$ probability that $P<.05)$, despite an apparently small $P$ value
(Table 3). We found only a $4 \%$ chance (Reliability) that the relationship between duration of support and posttransplant survival could be peaking. In addition, more sequential modes of MCS used, greater number of infections, and global sensitization were all associated with reduced survival after transplantation (Tables 3 and 4).

\section{Bridge-to-Transplant Survival}

Overall, accounting simply for duration of MCS, the probability of surviving both MCS and transplantation was $69 \%$ at onset of MCS, $65 \%$ at 1 month, $56 \%$ at 3 months, $47 \%$ at 6 months, and $29 \%$ at 12 months (Figure E4). These percentages were substantially altered by both patient- and 

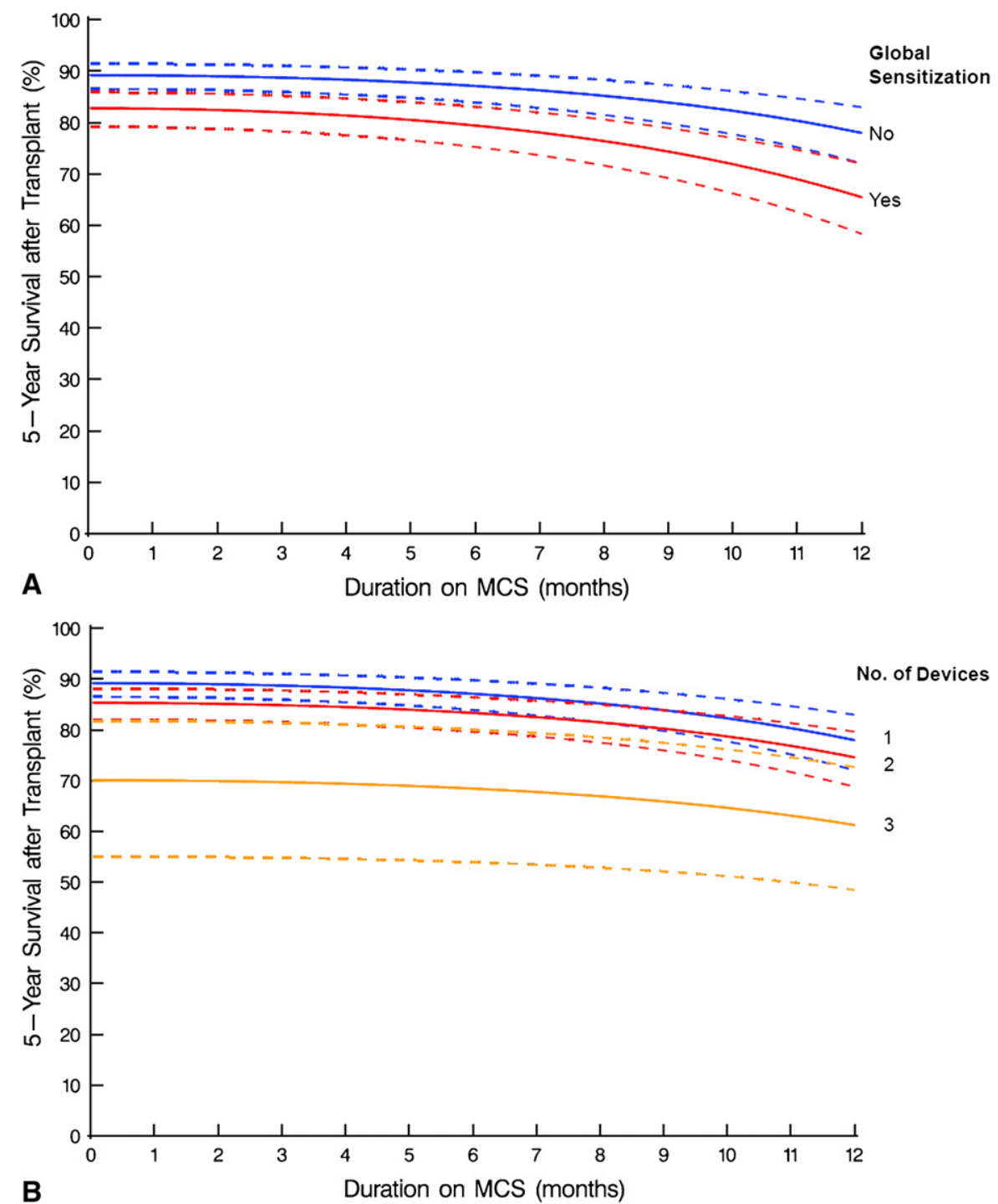

FIGURE 4. Five-year survival after transplant according to duration of MCS for a low-risk patient. Dashed lines represent $68 \%$ confidence limits of upper and lower curves. A, Survival simulated according to whether or not global sensitization had occurred on MCS. B, Survival after transplant simulated by number of devices implanted and subsequent transplantation.

device-related risk factors. Survival of a low-risk patient (baseline scenario; see "Optimal Timing of Transplant" under "Patients and Methods") was greatly affected by being globally sensitized or number of devices received (Figures 2 and $4, A, B)$.

\section{DISCUSSION \\ Principal Findings}

Transplant outcomes are strongly influenced by both preand post-MCS risk factors and events. Previous cardiac operation, need for ECMO or right ventricular assist device, poor renal function, HLA sensitization, and neurologic complications reduced survival after transplantation. Longer
MCS duration did not improve survival before transplant and may worsen survival after transplant.

\section{Survival}

Survival to and after transplant and overall survival after initiation of MCS was excellent and similar to other reports, even with inclusion of patients on short-term support. ${ }^{12}$ Survival difference between low- and high-risk groups was surprisingly large and similar in magnitude to a comparison of low- and high-risk patients supported long term with the HeartMate XVE device (Thoratec Corp, Pleasanton, Calif). ${ }^{13,14}$ Renal dysfunction and sepsis were 2 risk factors affecting survival. Longer duration of MCS may decrease 


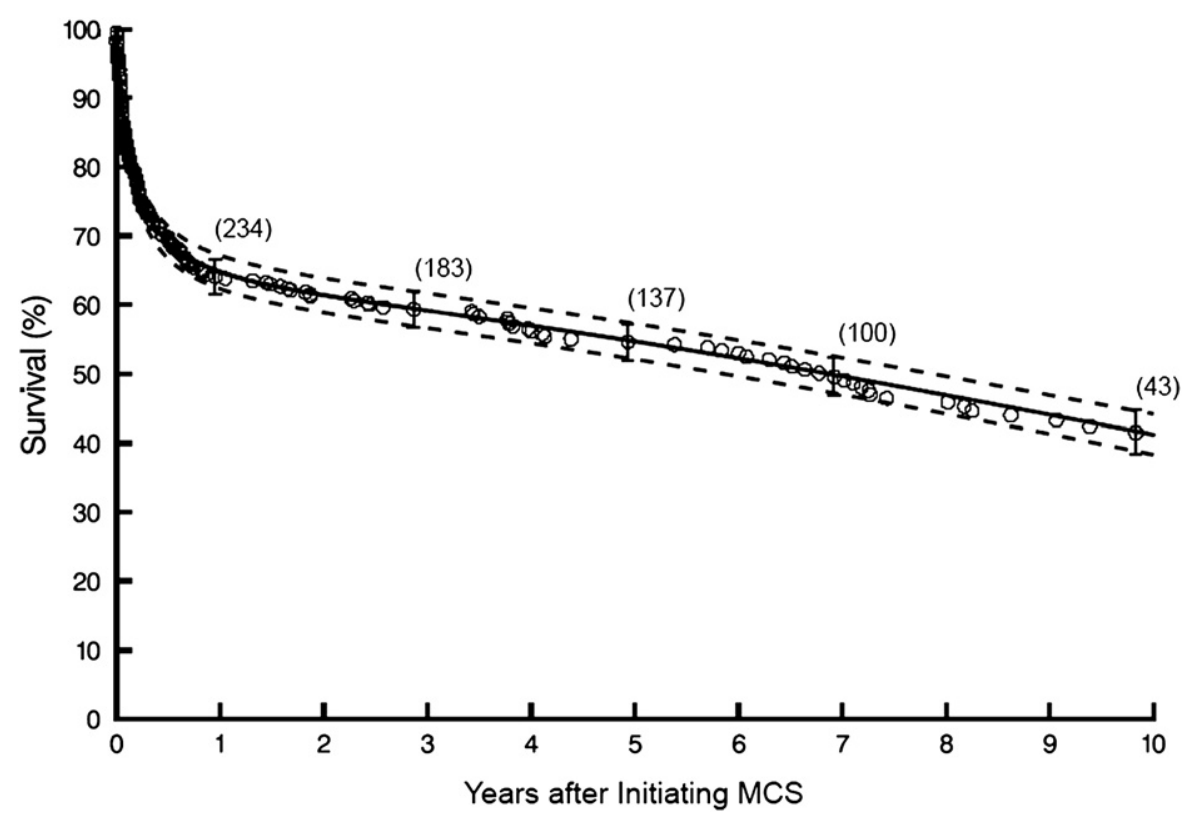

FIGURE 5. Overall survival after initiating MCS, regardless of time of transplant. Format is as in Figure 2.

survival to and after transplantation independently of other complications. This suggests that a cumulative burden of low- and high-frequency MCS complications (eg, device malfunctions and disconnects), patient and device mishaps (eg, cutting drivelines or simultaneously disconnecting batteries), and strokes and anticoagulation-related hemorrhages slowly diminish survival before and after transplantation. ${ }^{15}$ This has important implications for new-generation device management. Although continuous-flow pumps have fewer overall complications, these have not been eliminated and will continue to affect survival to and likely after transplantation. John and colleagues, ${ }^{16}$ for example, demonstrated that increased red blood cell transfusions and driveline infection with the Heartmate II device (Thoratec Corp) reduced survival after transplantation.

\section{Sequence of Mechanical Circulatory Support}

Sequential application of devices was associated with markedly reduced survival. Initiating MCS early with a single definitive device may improve survival before and after cardiac transplantation. Notably, the specific sequence of devices and duration of support did not increase risk above that already accounted for by the sequence number or choice of device type. This emphasizes, as Fitzpatrick and colleagues ${ }^{17}$ have shown, that survival is primarily determined by an early decision to implant univentricular or biventricular devices and not by choice of device type.

\section{Duration of Mechanical Circulatory Support}

We did not find a risk of early transplantation after initiating MCS, despite $17 \%$ of patients $(n=44)$ undergoing transplantation within 4 weeks. Pre-MCS characteristics of these patients were similar to those of patients undergoing transplantation later. Survival before and after initiation of MCS was relatively flat, with mortality increasing after 4 months of support. This finding is similar to that reported by John and colleagues, ${ }^{16}$ who studied the impact of duration of support for patients bridged with the HeartMate II device on survival. They observed excellent survival in the small group of patients who underwent transplantation in less than 30 days and found a trend toward increased mortality in those supported for more than 12 months. They speculated that this trend with longer duration of support could be due to sensitization.

Survival of the entire bridging program from initiating MCS through transplantation is rarely shown in the literature. However, this is the total risk to which a patient is exposed. The fact that a patient remains on support for more than 4 months at the Cleveland Clinic, when our average overall wait time as reported by the Scientific Registry of Transplant Recipients (www.ustransplants.org) is 2.7 months, and 2.5 months for patients on MCS (Figure E5), raised the possibility that longer duration of MCS was a surrogate for some mitigating circumstance delaying transplantation. Two possible explanations are the need to treat sensitization and infections; however, these complications did not occur more frequently in patients with longer durations of MCS, and sensitization independently reduced posttransplant survival.

\section{Sensitization}

There is general consensus that MCS increases the likelihood of sensitization. ${ }^{18-20}$ However, there is disagreement as 
TABLE 2. Incremental risk factors for death on mechanical circulatory support

\begin{tabular}{|c|c|c|c|}
\hline Factor & Estimate \pm SE & $\boldsymbol{P}$ & $\begin{array}{l}\text { Reliability } \\
(\%)^{*}\end{array}$ \\
\hline \multicolumn{4}{|l|}{ Early hazard phase } \\
\hline More devices & $1.2 \pm 0.25$ & $<.0001$ & 87 \\
\hline Pre-MCS higher BP at diastole $\dagger$ & $1.1 \pm 0.49$ & .02 & 45 \\
\hline Pre-MCS higher creatinine $\ddagger$ & $-1.7 \pm 0.75$ & .03 & 57 \\
\hline Pre-MCS higher bilirubin & $0.40 \pm 0.14$ & .006 & 59 \\
\hline ECMO or RVAD & $2.8 \pm 0.69$ & $<.0001$ & 96 \\
\hline \multicolumn{4}{|l|}{ Late hazard phase } \\
\hline Age & & & 57 \\
\hline Younger age $\S$ & $1.3 \pm 0.28$ & $<.0001$ & \\
\hline Older age $^{\|}$ & $1.8 \pm 0.42$ & $<.0001$ & \\
\hline Pre-MCS lower cardiac index 9 & $3.7 \pm 1.1$ & .0006 & 69 \\
\hline $\begin{array}{l}\text { Pre-MCS lower PA pressure at } \\
\text { systole }^{\#}\end{array}$ & $-1.6 \pm 0.61$ & .008 & 54 \\
\hline Pre-MCS higher creatinine** & $0.087 \pm 0.022$ & $<.0001$ & 74 \\
\hline Neurologic complication & $1.6 \pm 0.61$ & .003 & 42 \\
\hline \multicolumn{4}{|c|}{$\begin{array}{l}B P \text {, Blood pressure; } B S A \text {, body surface area; } E C M O \text {, extracorporeal membrane oxy- } \\
\text { genation; } I A B P \text {, intra-aortic balloon pumping; } M C S \text {, mechanical circulatory support; } \\
P A \text {, pulmonary artery; } R V A D \text {, right ventricular assist device; } S E \text {, standard error. *Per- } \\
\text { cent of times factor appeared in } 500 \text { bootstrap analyses. } \dagger(\mathrm{BP} \text { at diastole/ } / 60)^{2} \text {, squared } \\
\text { transformation. } \ddagger(1 / \text { creatinine), inverse transformation. } \$(50 / \text { age }) \text {, inverse transforma- } \\
\text { tion. "(Age } / 50)^{2} \text {, squared transformation. } \uparrow(1 / \text { cardiac index), inverse transformation. } \\
{ }^{*} \text { Log(PA pressure at systole), logarithmic transformation. }{ }^{* *}(\text { Creatinine })^{2} \text {, squared } \\
\text { transformation. }\end{array}$} \\
\hline
\end{tabular}

to its importance. ${ }^{21,22}$ This disagreement in part reflects variability in the type of test used, its interpretation, and the fact that HLA antibodies after MCS are for the most part nonspecific. Because the majority of the hearts we use are imported, precluding prospective cross-matching of sensitized patients, we have used "virtual matching," comparing donor HLA type with known quantities of specific anti-donor HLA antigens. ${ }^{23}$ Although this facilitates transplantation, $30 \%$ of our patients receiving imported hearts have some degree of weakly positive posttransplant cross-matches as determined by flow cytometry, ${ }^{23}$ and this is associated with

TABLE 3. Incremental risk factors for death after transplantation among mechanical circulatory support patients surviving to transplantation

\begin{tabular}{lcll}
\hline \multicolumn{1}{c}{ Factor } & Estimate \pm SE & $\boldsymbol{P}$ & Reliability $(\%)^{*}$ \\
\hline Early hazard phase & & & \\
$\quad$ More modes of MCS & $1.5 \pm 0.53$ & .005 & 40 \\
More blood infections & $0.31 \pm 0.092$ & .0008 & 61 \\
Late hazard phase & & & \\
Longer duration on MCS (y) $\dagger$ & $0.85 \pm 0.15$ & $<.0001$ & 23 \\
More neurologic complications & $0.43 \pm 0.17$ & .01 & 51 \\
Global sensitization $\ddagger$ & $0.56 \pm 0.26$ & .03 & 51 \\
Poor renal function $\S$ & $0.32 \pm 0.502<.0001$ & 68 \\
Previous cardiac operation & $0.75 \pm 0.25$ & .003 & 64 \\
\hline
\end{tabular}

$M C S$, Mechanical circulatory support; $S E$, standard error; $T$-PRA, T-cell panel reactive antibody. *Percent of times factor appeared in 500 bootstrap analyses. $\dagger$ (Duration on MCS $)^{2}$, squared transformation. $\ddagger$ Any of the following: specifically sensitized, needing plasmapheresis, needing induction therapy, T-cell PRA $>10 \%$. $\S$ Exp(blood urea nitrogen at transplant/40), exponential transformation.
TABLE 4. Adverse events occurring on mechanical circulatory support

\begin{tabular}{lcc}
\hline \multicolumn{1}{c}{ Event } & $\mathbf{n}^{*}$ & No. $(\%)$ \\
\hline $\begin{array}{l}\text { Adverse events on MCS }(\mathrm{n}=375) \\
\quad \text { Neurologic }\end{array}$ & 363 & $100(28)$ \\
Infection & & \\
$\quad$ Driveline & 363 & $73(20)$ \\
$\quad$ Pump-pocket & 363 & $53(15)$ \\
$\quad$ Other & 363 & $98(27)$ \\
Reoperation for bleeding & 363 & $91(25)$ \\
Device failure & 363 & $15(4.1)$ \\
Adverse MCS events among transplant recipients $(\mathrm{n}=262)$ & \\
Neurologic & 252 & $57(23)$ \\
Infection & & \\
$\quad$ Driveline & 252 & $67(24)$ \\
$\quad$ Pump-pocket & 252 & $41(16)$ \\
$\quad$ Other & 252 & $57(23)$ \\
Reoperation for bleeding & 252 & $57(23)$ \\
Device failure & 252 & $8(3.2)$ \\
Global sensitization & 253 & $137(59)$ \\
\hline
\end{tabular}

MCS, Mechanical circulatory support. *Data available.

an increased frequency of humoral, acute, and chronic cellular rejection and decreased survival. ${ }^{24}$

\section{Strengths and Limitations}

This was an observational study encompassing 15 years, during which multiple surgeons cared for patients, and numerous devices, clinical practices, and therapies were introduced and others abandoned. Confounding our analysis effort was nonstandardized approaches to MCS, variable assessment and treatment of sensitized patients, induction therapy and plasmapheresis, which can suppress immune function, and unrecognized surgical biases for a specific device and timing of transplantation. One of the study's strengths, however, is that a substantial number of patients underwent transplantation after a short duration of MCS.

We did not measure quality-adjusted life years, mental and emotional status, or costs, all of which may be important outcomes from patient, payor, and society perspectives. We did not, in this subset of transplant recipients, investigate donor variables that are well known to affect survival after transplantation, particularly in sensitized patients. There may be institutional or individual confounding effects on results. Finally, only 11 patients in our cohort were supported with continuous-flow pumps. Recent reports have demonstrated this technology to be more durable and reliable than pulsatile support, and although not totally eliminated, pump thrombosis, thromboembolism, and device-related infection seem to be lower than with pulsatile support (at 18 months post-implant). ${ }^{25}$

\section{CONCLUSIONS}

Our study suggests that initiating MCS early and with a single definitive mode of support may improve survival 
before and after transplantation. Performing transplantation in the patient as soon as possible, not necessarily fully recovered, may be prudent. Although virtual cross-matching is convenient, it requires further validation before replacing prospective cross-matching in highly sensitized individuals. Initiating MCS early with a single definitive device may improve survival to and after cardiac transplantation. Early transplant, which avoids infection, sensitization, and neurologic complications, may improve bridge and transplant survival.

\section{References}

1. Taylor DO, Edwards LB, Boucek MM, Trulock EP, Waltz DA, Keck BM, et al. Registry of the International Society for Heart and Lung Transplantation: twentythird official adult heart transplantation report-2006. J Heart Lung Transplant. 2006;25:869-79.

2. Gammie JS, Edwards LB, Griffith BP, Pierson RN 3rd, Tsao L. Optimal timing of cardiac transplantation after ventricular assist device implantation. J Thorac Cardiovasc Surg. 2004;127:1789-99.

3. Kirklin JK, Naftel DC, Bourge RC, McGiffin DC, Hill JA, Rodeheffer RJ, et al. Evolving trends in risk profiles and causes of death after heart transplantation: a ten-year multi-institutional study. J Thorac Cardiovasc Surg. 2003;125: 881-90.

4. Sun BC, Catanese KA, Spanier TB, Flannery MR, Gardocki MT, Marcus LS, et al. 100 long-term implantable left ventricular assist devices: the Columbia Presbyterian interim experience. Ann Thorac Surg. 1999;68:688-94.

5. Jaski BE, Kim JC, Naftel DC, Jarcho J, Costanzo MR, Eisen HJ, et al. Cardiac transplant outcome of patients supported on left ventricular assist device vs. intravenous inotropic therapy. J Heart Lung Transplant. 2001;20:449-56.

6. Kormos RL, Breen TJ, Frazier OH, Hosenpud JD. Sub-study analysis of ISHLT/ UNOS Registry, Richmond, VA: use of ventricular assist devices before heart transplant effects of type of support on transplant survival. J Heart Lung Transplant. 1995; 14:S67.

7. Betkowski AS, Graff R, Chen JJ, Hauptman PJ. Panel-reactive antibody screening practices prior to heart transplantation. J Heart Lung Transplant. 2002;21:644-50.

8. Kumpati GS, Cook DJ, Blackstone EH, Rajeswaran J, Abdo AS, Young JB, et al. HLA sensitization in ventricular assist device recipients: does type of device make a difference? J Thorac Cardiovasc Surg. 2004;127:1800-7.

9. Kalbfleisch JD, Prentice RL. The Statistical Analysis of Failure Time Data. New York: Wiley; 1980.

10. Blackstone EH, Naftel DC, Turner ME Jr. The decomposition of time-varying hazard into phases, each incorporating a separate stream of concomitant information. J Am Stat Assoc. 1986;81:615-24.

11. Breiman L. Bagging predictors. Machine Learning. 1996;24:123-40.

12. Morgan JA, John R, Rao V, Weinberg AD, Lee BJ, Mazzeo PA, et al. Bridging to transplant with the HeartMate left ventricular assist device: The Columbia Presbyterian 12-year experience. J Thorac Cardiovasc Surg. 2004;127:1309-16.

13. Miller LW, Lietz K. Candidate selection for long-term left ventricular assist device therapy for refractory heart failure. J Heart Lung Transplant. 2006;25: 756-64.

14. Lietz K, Long J, Kfoury AG, Slaughter MS, Silver MA, Milano CA, et al. Outcomes of left ventricular assist device implantation as destination therapy in the post-REMATCH era: implications for patient selection. Circulation. 2007;116:497-505.

15. Deng MC, Edwards LB, Hertz MI, Rowe AW, Keck BM, Kormos R, et al. Mechanical Circulatory Support Device Database of the International Society for Heart and Lung Transplantation: second annual report-2004. J Heart Lung Transplant. 2004;23:1027-34.

16. John R, Pagani FD, Naka Y, Conte JV, Klodell CT, Milano CA, et al. Duration of LVAD support does not impact post-cardiac transplant survival in the continuousflow pump era. Presented at the 89th Annual Meeting of the American Association for Thoracic Surgery, May 9-11, Boston, 2009.

17. Fitzpatrick JR 3rd, Frederick JR, Hiesinger W, Hsu VM, McCormick RC, Kozin ED, et al. Early planned institution of biventricular mechanical circulatory support results in improved outcomes compared with delayed conversion of a left ventricular assist device to a biventricular assist device. J Thorac Cardiovasc Surg. 2009;137:971-7.

18. Moazami N, Itescu S, Williams MR, Argenziano M, Weinberg A, Oz MC. Platelet transfusions are associated with the development of anti-major histocompatibility complex class I antibodies in patients with left ventricular assist support. J Heart Lung Transplant. 1998;17:876-80.

19. Massad MG, Cook DJ, Schmitt SK, Smedira NG, McCarthy JF, Vargo RL, et al. Factors influencing HLA sensitization in implantable LVAD recipients. Ann Thorac Surg. 1997;64:1120-5.

20. Itescu S, Tung TC, Burke EM, Weinberg A, Moazami N, Artrip JH, et al. Preformed IgG antibodies against major histocompatibility complex class II antigens are major risk factors for high-grade cellular rejection in recipients of heart transplantation. Circulation. 1998;98:786-93.

21. Pagani FD, Dyke DB, Wright S, Cody R, Aaronson KD. Development of anti-major histocompatibility complex class I or II antibodies following left ventricular assist device implantation: effects on subsequent allograft rejection and survival. J Heart Lung Transplant. 2001;20:646-53.

22. Joyce DL, Southard RE, Torre-Amione G, Noon GP, Land GA, Loebe M. Impact of left ventricular assist device (LVAD)-mediated humoral sensitization on posttransplant outcomes. J Heart Lung Transplant. 2005;24:2054-9.

23. Gupta S, Cook DJ, Sharma M, Stawinski G, Taylor D, Yamani MH, et al. Virtual crossmatching" allows the expansion of effective donor pool for HLA-sensitized patients [abstract]. J Heart Lung Transplant. 2006;25:S140.

24. Bishay ES, Cook DJ, Starling RC, Ratliff NB Jr, White J, Blackstone EH, et al. The clinical significance of flow cytometry crossmatching in heart transplantation. Eur J Cardiothorac Surg. 2000;17:362-9.

25. Pagani FD, Miller LW, Russell SD, Aaronson KD, John R, Boyle AJ, et al. Extended mechanical circulatory support with a continuous-flow rotary left ventricular assist device. J Am Coll Cardiol. 2009;54:312-21.

\section{Discussion}

Dr J. Kirklin (Birmingham, Ala). This is an elegant and sophisticated analysis that takes on a complex and controversial issue in cardiac transplantation. As you know, Nick, we previously analyzed the information from the Cardiac Transplant Research Database, and as you did at the Cleveland Clinic, we found that there was a progressive increase in risk for the longer duration of support before cardiac transplantation. The one difference was that we also found an increased risk, as have some other studies, in the first 2 weeks more or less. So this is the crux of the matter in this analysis.

Many transplant centers, and in fact most now, have a general policy of more or less 30 days, if the patient is, as you say, ambulatory and his/her subsystem dysfunction is reversed, to go ahead and activate for transplantation. So the real core of the issue of a potential controversy exists in that first 3 to 4 weeks. To enlighten us and help us analyze or perhaps judge the efficacy of your model in really addressing that first period after the patient receives the device, 2 questions.

Many other analyses have indicated that increasing risk of duration of time on support has a major effect on the early phase of risk after cardiac transplantation. We found that for both increase in duration of support and very early transplantation. To what do you attribute your finding that it was only operative in the late phase of hazard after cardiac transplantation, which I find a little bit curious?

Second, and more important, you mention in your article that $17 \%$ of the patients actually underwent transplantation within 30 days of receiving their device. So this is the cohort of special interest. Did you have the opportunity to look specifically at the patient characteristics or profiles of that $17 \%$ who actually had a transplant within 30 days of the device? For example, were these so-called INTERMACS class I, in cardiogenic shock, did they receive ECMO support or other short-term device, and if so, what really played in the clinician's mind to allocate transplantation of them early as opposed to switching to a more durable device? And for those who had a durable device, what were the patient profiles? Do we have evidence they had insufficient reversal of organ dysfunction at the time you performed transplantation that would help support 
your recommendation that we should proceed even before there is reversal of organ dysfunction?

Dr Smedira. Thanks, Jim, for your comments, and I would first like to take this opportunity to recognize Dr Kirklin for his contributions, both the transplant database and now with the development of the INTERMACS registry, which I think will help enlighten us and answer some of these questions. Let me answer 2 first and then go back and speculate on the first question.

Seventeen percent of our patients underwent transplantation within 4 weeks. Nine of our patients underwent transplantation off of ECMO or the BVS 5000 system (ABIOMED, Inc, Danvers, Mass). We could not find anything that distinguished those cohorts receiving transplants early or late. There were no distinguishing characteristics. I think it was the philosophy of the surgeons that this person was best served by going straight to transplantation. That is a surprise to me, because even within my own institution I didn't think we were doing that, but in fact my colleagues were, and the results weren't bad.

As for implantable devices, as I said, I used to hold the bar up to 15 minutes on the treadmill before I would activate a patient. Again, my colleagues would go sooner. And so I think the way I put this together is if the patient has recovered organ function, is ambulatory and doing well, there is really no contraindication to proceed with transplantation. It was difficult to define anything unique about these early transplant recipients.

Now, why do they have a decrement at 3 to 5 years? I looked closely at your article in the Journal, and you showed there was a relative risk of approximately 1.46 in those undergoing transplantation after 6 months, if I remember correctly, and you said your early phase went from 30 days to 2 years. Now, my best guess is it is probably some immune-mediated problem related to the device. Now, most of our patients had HeartMate devices, and we had some Novacor devices (World Heart Inc, Salt Lake City, Utah), and there is a great deal of information about the device surface activating the immune system. So my best guess for why this would be showing up at the 2- to 3-year mark is some immune activation. We saw that it was much worse in the patients who were infected and sensitized, and we know those patients are immuneactivated. So I think it is a synergistic activation of those factors.

Dr J. Conte (Baltimore, $M d$ ). Nick, a very nice presentation, but as I was sitting here listening, I am really not sure what the takehome message is. My current practice is to put the ventricular assist device in; the patient recovers, is discharged, and returns to the clinic every week thereafter; and once the patient mentally and physically feels good, and the laboratory values are good, we think the patient has recovered. If the patient is walking around, doing well at home, then we list him/her for transplantation. A couple of years ago that is what UNOS told us was appropriate for us to now begin the patient's status 1a time. Once the transplant team thought the patient was ready for transplant, we could go ahead and list him/her.

If you have a patient who is doing well after ventricular assist device implantation, at what point exactly are you saying we ought to perform transplantation in these patients? Because we may be doing the same thing. I am not really sure what you are doing, but could you be specific about that?

Dr Smedira. Let me address the first part of that. What we saw in these patients who are discharged, brought back, and are doing fine and everything is looking good, is that we lose patients as we wait for them to become perfect candidates. We have had patients whom we wanted to recover a bit and learn a bit more how to deal with their device, and they have died of strokes before we were able to activate them. Any of you in the business has seen the recent notifications of HeartMate II outflow cannula disconnect where the patient died. We had a recent patient who just required an emergency operation because fluid was aspirated in the vent. My impression is the longer you keep patients on the device, you run the risk of device and patient interaction and malfunction, and you will lose some patients. When the patient is, to your best estimate, ready to undergo another operation, he/she should be activated for transplantation with the bar not set excessively high.

Dr Conte. I think I agree with you, but what time are you saying?

Dr Smedira. Our study says it doesn't matter. And I know my colleague, Dr Banbury, is here, and if he saw the patient was sitting up and could move around, it is time to undergo transplantation. Could be 2 weeks, 7 days, 10 days, a different approach. In our analysis, going in early, within 4 weeks, did not affect survival.

Dr Conte. The paradigm that most people have is an LVAD is implanted; they recover. Yours is a little bit different.

Dr Smedira. That has always been our paradigm, the patient recovery. The question is, is that the smartest and safest thing to do? What we showed is we don't have any negative impact by performing transplantation in patients as soon as they seem ready for it.

Dr Conte. I guess what I was looking for was more of a black and white.

Dr Smedira. There is no black and white.

Dr L. von Segesser (Lausanne, Switzerland). When you list a patient, how much waiting time is there?

Dr Smedira. For these patients, our median support time was 2.7 months, and for our transplant recipients, our median wait time is 2.4 months.

Dr Von Segesser. So if you say you decided a patient was ready now, he would have to wait how long?

Dr Smedira. A couple of weeks at most.

Dr P. Portner (Stanford, Calif). I enjoyed your presentation, Nick. It was very interesting. I am trying to understand exactly what you said, but you are not suggesting that in your practice, or your combined practice, that you in fact keep patients on devices just because they are doing well beyond the time that you could in fact list them, and then the time to transplant is in fact whatever it takes to receive a donor? Because there are some people who have been suggesting that having a patient with no morbidity, extend that period of time, although you have an ongoing potential risk, extends the time that you give them when you add that to the transplantation.

Dr Smedira. I had believed in that philosophy, but now I think that from our data we would suggest that you lose more patients by doing that than by moving forward to transplant as soon as they are ready.

Dr Portner. At the end of the day, though, it is a subjective decision as to when you list them, right?

Dr Smedira. Yes, it always is. It is a clinical decision trying to balance the risk of going to transplantation at this time and the risk of events occurring on the device.

Dr Portner. In your earlier response to Jim Kirklin, with the 17 patients you have analyzed in the first month, are you suggesting 
that you wouldn't even wait for that early postoperative, potentially morbid period? You would go ahead and list them immediately or you still have some time that you would allow for early recovery?

Dr Smedira. It depends on what the recovery is. If you have somebody with an acute myocardial infarction, cardiogenic shock, you put an LVAD in and 5 days later he has a creatinine of 1 , he is sitting up, eating food, and watching the Ohio State football game, that guy is ready for transplantation, and it has only been 9 days, but in the past I would say, well, he has to be on the treadmill. But this guy wasn't ill 5 days ago and he has now recovered from an uneventful VAD. You move forward with the transplantation with 9 days of support. 


\section{APPENDIX E1. Variables considered in the analyses}

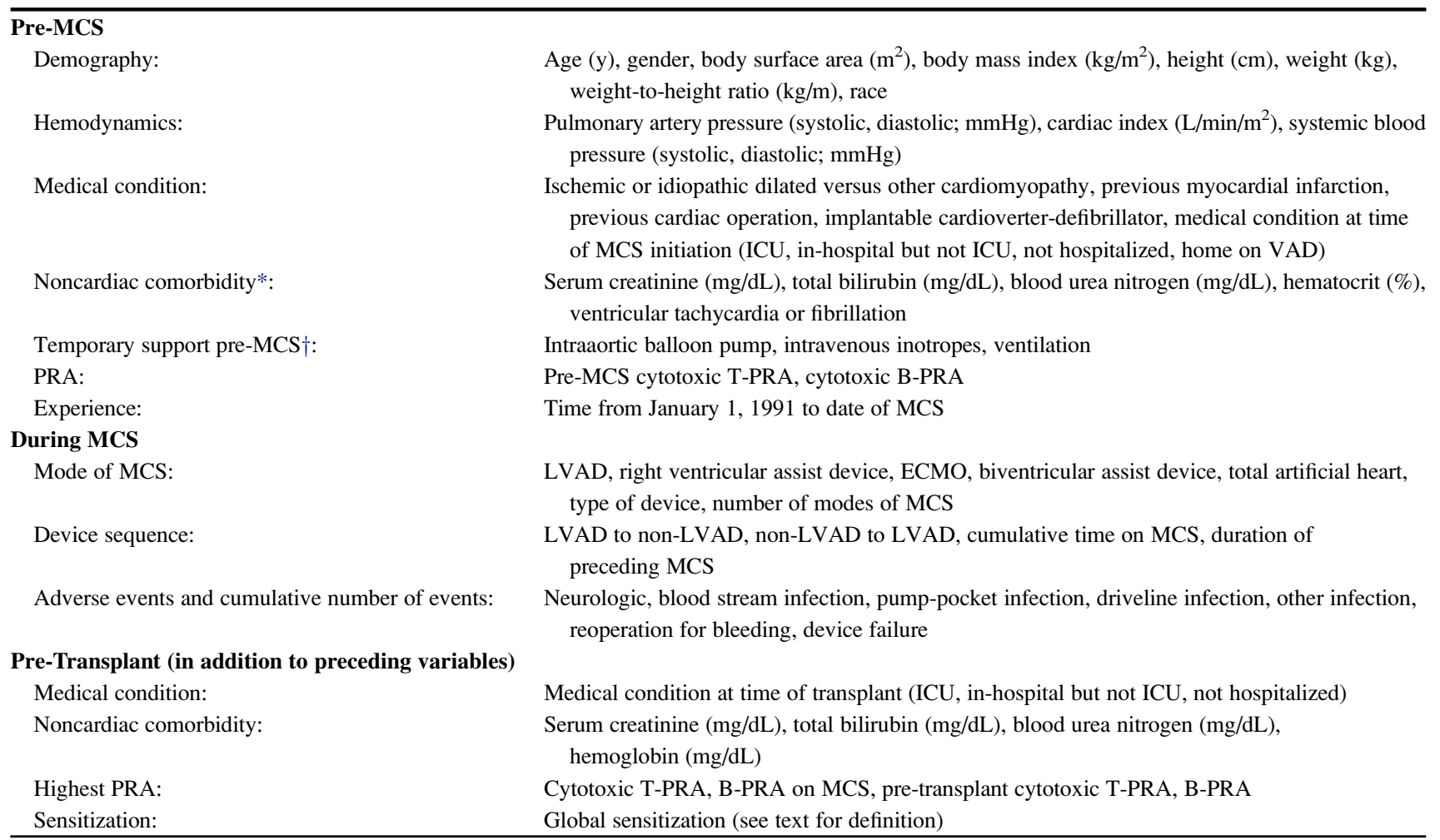

$M C S$, Mechanical circulatory support; $I C U$, intensive care unit; $E C M O$, extracorporeal membrane oxygenation; $V A D$, ventricular assist device; $L V A D$, left ventricular assist device; $P R A$, panel reactive antibody; $T$-PRA, T-cell panel reactive antibody; $B-P R A, \mathrm{~B}$-cell panel reactive antibody. $*$ Within $72 \mathrm{~h}$ of implantation. $\dagger$ Within $72 \mathrm{~h}$ of implantation. 


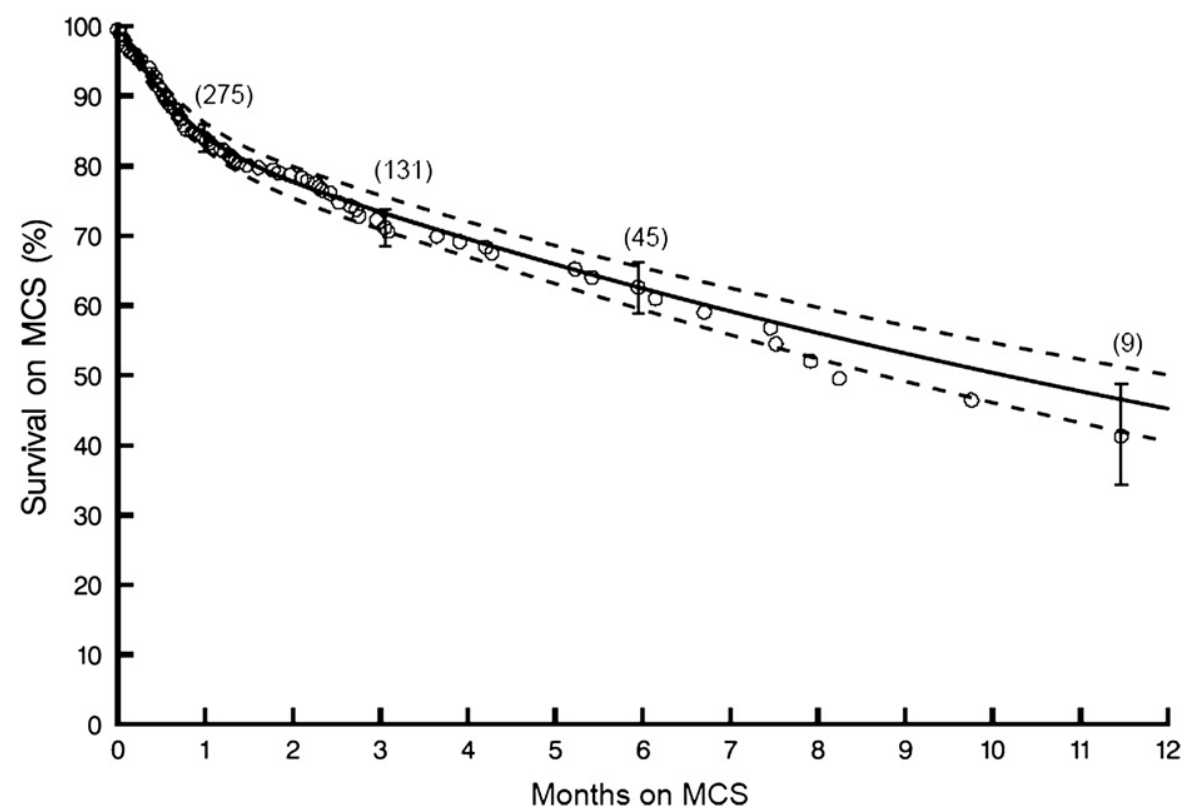

FIGURE E1. Overall survival on MCS, with patients censored at transplant. Each symbol represents a death, vertical bars represent $68 \%$ confidence limits (equivalent to \pm 1 standard error), and numbers in parentheses represent patients remaining at risk.

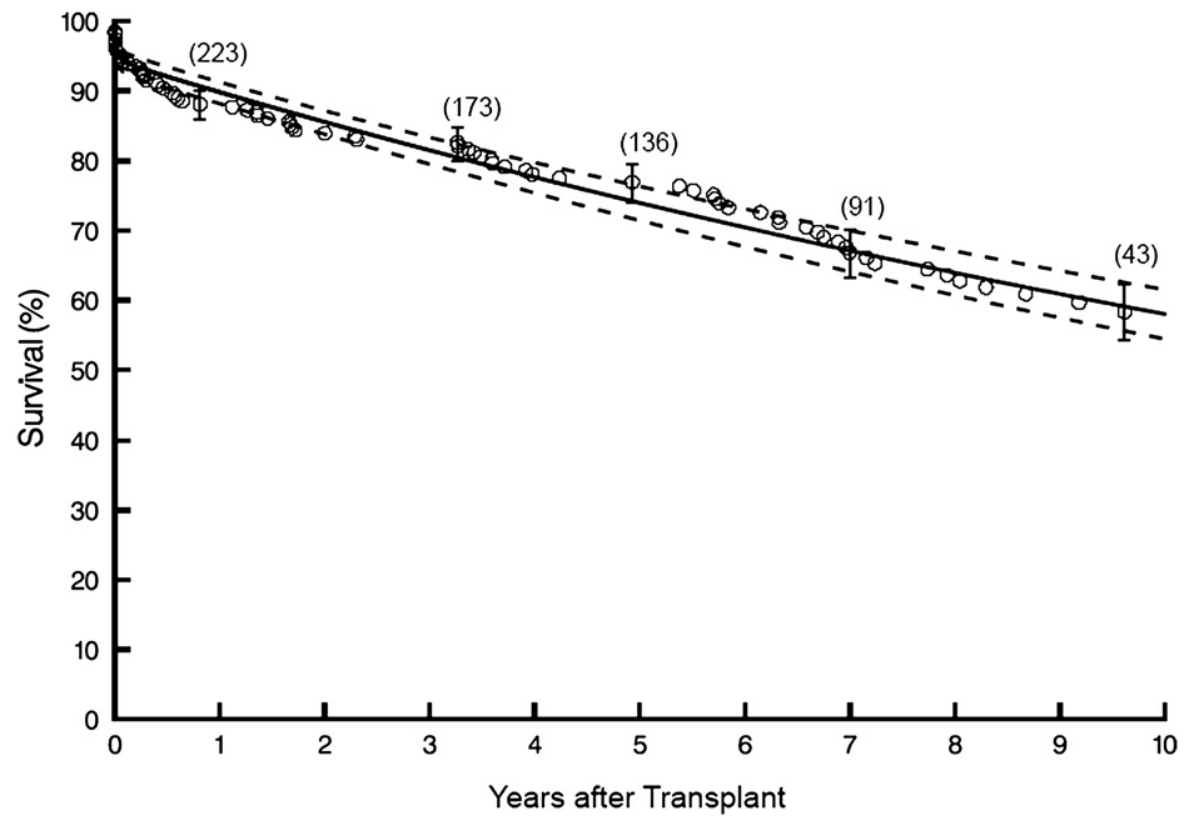

FIGURE E2. Survival after transplant of patients surviving MCS. Format is as in Figure E1. 

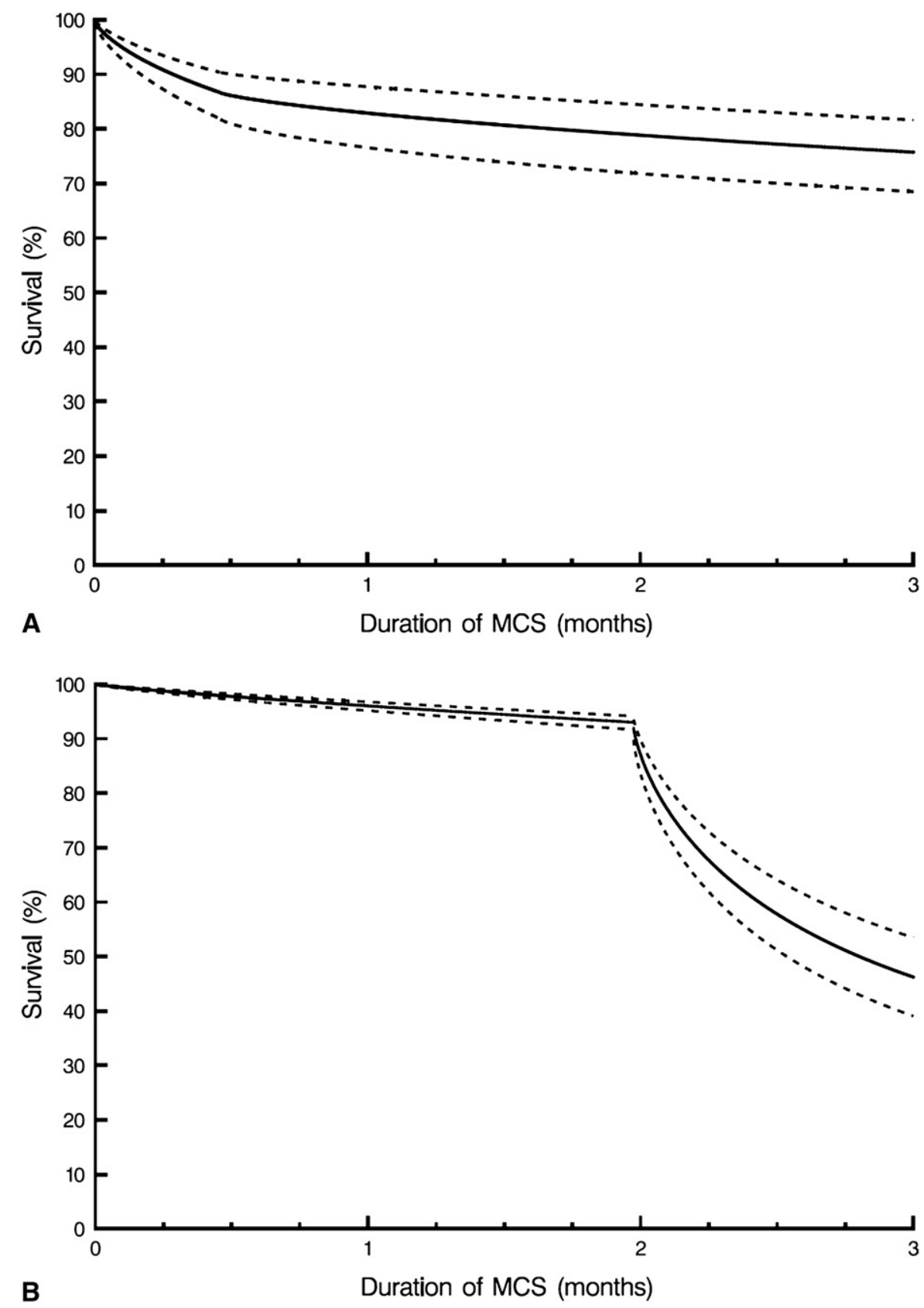

FIGURE E3. Survival on MCS. Solid line is point estimate based on Table 2, and dashed lines are $68 \%$ confidence limits from modulated renewal analyses. A, Baseline patient has MCS initiated with a non-LVAD device for 2 weeks and then requires LVAD support. B, Baseline patient has MCS initiated with an LVAD, but at 2 months requires non-LVAD support. 


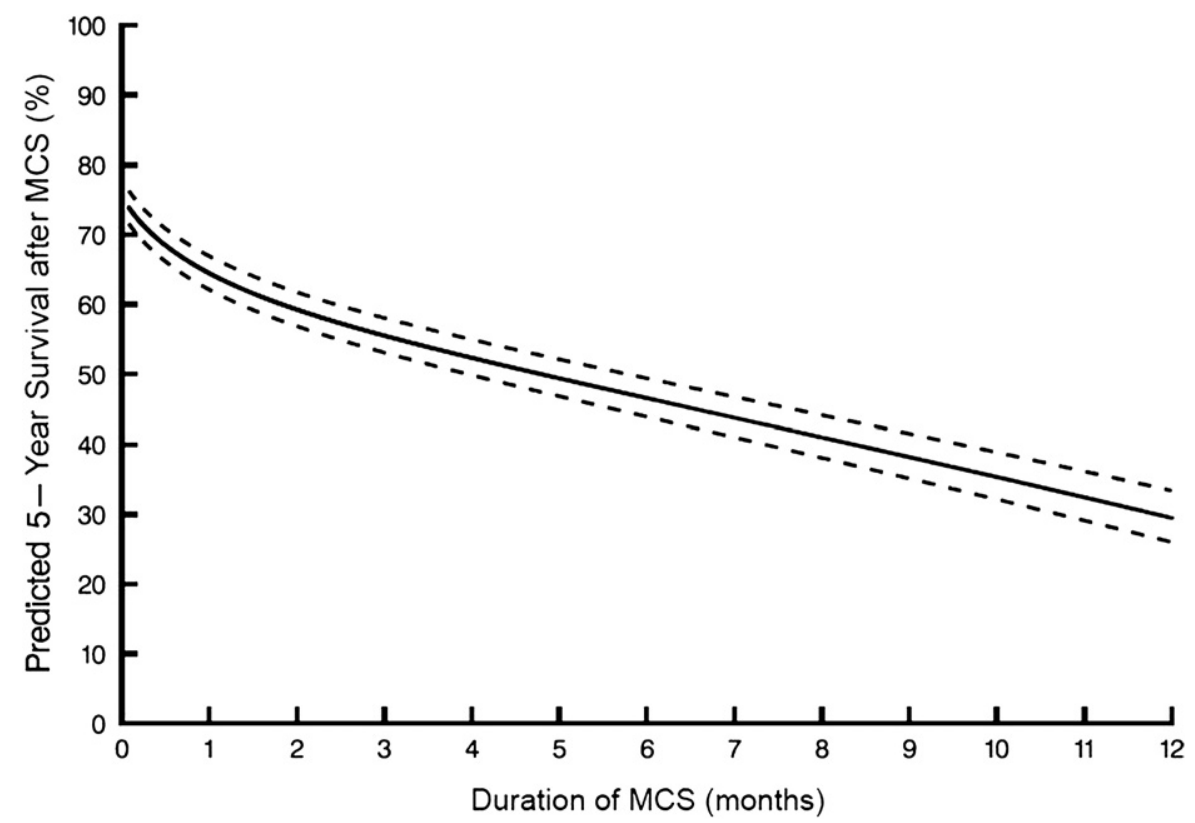

FIGURE E4. Predicted probability of surviving both MCS and transplant to 5 years after initiating MCS according to duration of MCS. Dashed lines are estimated $68 \%$ confidence limits.

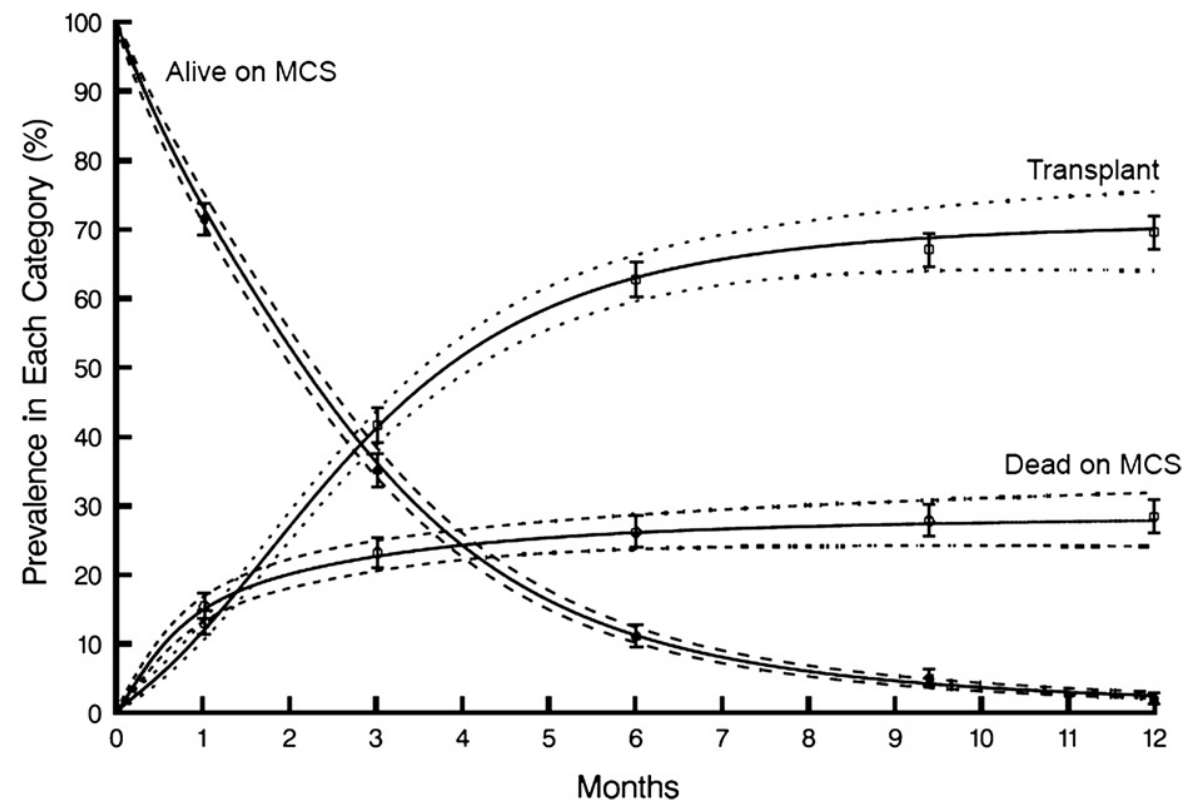

FIGURE E5. Competing risks of remaining alive on MCS, dying on MCS, and undergoing transplantation. All probabilities add to $100 \%$. Thus, for example, "Alive on MCS" is equivalent to the distribution times on MCS. 